\title{
Natural measures of normalization of vital systems of the person for maintaining of the healthy state
}

\begin{abstract}
The World Health Organization reads that the organism status only for $5 \%$ depends on services of health care, for $10 \%$ of the environment, for $10 \%$ of heredity, for $5 \%$ of a supply and for $70 \%$ of a way of life. The healthy status of people reaches and supports by a healthy lifestyle. The healthy status is reached by setup of vital systems and integral normal functioning of an organism. The scientist and doctor Avicenna was convinced: The person, moderately both timely engaged in physical exercises and realizing natural measures of normalization of vital systems, does not need treatment. The person reaches and supports a healthy status in the environmentally friendly natural and spiritual social environment by the healthy lifestyle including preventive health the supporting spiritual and solid cleanings up and also physical exercises of normalization, first, physiological rhythms gymnastics, secondly, of a power system charging, thirdly, of a tone of muscles of an organism physical culture. For this purpose it is necessary to create health the preserving health care system on the basis of a healthy lifestyle. ${ }^{1-15}$ Natural measures of normalization of vital systems of the person are briefly covered in article.
\end{abstract}

Keywords: healthy status, vital systems, physiological normalization, healthy lifestyle, health care, self-restoration
Volume 3 Issue I - 2018

Evgeniy Bryndin,' Irina Bryndina ${ }^{2}$

'Research Centre Nature Informatics, Technological Platform Future Medicine, Russia

${ }^{2}$ Pediatric Faculty, Novosibirsk State Medical University, Russia

Correspondence: Evgeniy Bryndin, Research Centre Nature Informatics, Technological Platform Future Medicine, Novosibirsk, Russia, Email bryndin@ngs.ru

Received: December 09, 2017 | Published: January 19, 2018

\section{Introduction}

In modern conditions illness is the reason of $75 \%$ of absence from work. The aspiration to conservation of health, to be exact to concealment of pathology, was already shown in today's market relations. It is caused by the fact that the population doesn't want not to come to work since it can get laid off and be the unemployed, once again. Therefore, patients have more chances to become the unemployed, than at healthy. Important it because frequent illness of working won't allow framing material benefits, i.e. profiting to the enterprise; in case of illness or a trauma the employer is obliged to pay to the patient temporary disability benefit. Therefore it is much more favorable to employer to employ healthy faces, than patients with the low level of health. In this regard at the population in the conditions of market economy arises motivations to conservation of health. The population understands that health is an invaluable social quality which needs to be kept and increased greatly. ${ }^{1-4}$ The person understands that exciting to be more expedient, than the patient.

The modern medical medicine leans, generally, on the pharmaceutical industry. Chemical drugs are carcinogens which impact on an organism increases probability of emergence of foreign matters in an organism, at worst cancer educations. After treatment the patient keeps addictions and former habitual not a healthy lifestyle and hopes only for drugs for improvement of health which cease to help it over time. Prophylaxis of medical medicine is directed to fight against widespread diseases of impact of medicinal preparations on the particular systems of an organism. The medical medicine prolongs life to patients, but doesn't make them healthy.

The healthy condition of an organism is supported by all biotic systems: mental, power, physiological, anatomic and spiritual. Their daily control is for this purpose necessary. ${ }^{5-10}$ Control of vital systems consists in normalization of operation of mechanisms of realization of their functions. Her person carries out charging, gymnastics, physical culture in the environmentally friendly environment and other measures. Has to be result of control balanced mentality, normal rhythms of walking, respiration and pulse, balance of exaltation and inhibition of a nervous system, hormonal equilibrium, balance of inflow and outflow of a blood of a brain and acid-base balance of all biological mediums, normal integrated functioning of an organism.

Control of difficult essence of the person is also carried out at the power and spiritual level. Control is carried out by natural measures and turns into a healthy habit within a month emotional fixing.

\section{System of internal respiration}

The system of internal respiration needs to be customized daily in the morning after a dream, remission of an organism of the collected gases a continuous expiration, raising knees and pressing them on area of a stomach and breast. The expiration is carried out until the organism doesn't demand saturation of cells oxygen. Then saturation of cells of an organism with oxygen and their remission of a carbon dioxide in the course of walking 64 steps a minute is counterbalanced, on four steps the inspiration through a nose and on four steps exhaled.

Important vital constant of an organism on which it is possible to judge functioning of an organism is carbonei dioxydum, allocated by an organism and partially detained in it. The basic purpose of the remaining carbonei dioxydum consists in maintenance in an arterial blood of concentration of carbonic acid on which level providing cells of organs and tissues with oxygen, more precisely, blood deoxygenation degree, that is returns of oxygen by it to cells owing to weakening of a chemical bond of molecules of oxygen with a hemoglobin depends. At contents at the level of $6,5 \%$ processes of a deoxygenation of a blood take place in carbonei dioxydum blood normally (effect of Verio - Bohr). Cells of all organs and tissues in prosperity receive oxygen. Transition of oxygen to cells and tissues exempts them from excess of a carbon dioxide. Cellular internal respiration by gas exchange of oxygen and a carbon dioxide is normalized. 


\section{System of external respiration}

The system of external respiration is customized through nasal respiration. Nasal respiration will be compounded with an exercise stress in the course of walking 64 steps a minute, at an inspiration on four steps and an exhalation on four steps minute with concentration of attention in a stomach, a breast, a larynx and pneumatic sinuses. Nasal respiration frames pressure below atmospheric in an abdominal cavity, that is negative, and in an abdominal cavity - positive. It normalizes the movement of a blood on veins of legs to heart at the expense of the difference of pressure in an abdominal cavity. Nasal respiration by aeroions of air normalizes the content of carbonei dioxydum in number of $6,5 \%$ that allows a blood flow to provide supply of all cells of an organism with oxygen. At the same time the blood leaving a pulmonary artery is loaded with negative potential. The air which is plentifully sated with aeroions inhale to being in mountains, on the sea coast, about springs, in the coniferous wood. At nasal respiration exaltation and inhibition of a nervous system is counterbalanced and pressure is normalized. At respiration through a nose, the mucosa of a nose detains viruses, getting from air, without allowing them to get into lungs and to initiate inflammatory processes.

\section{Visual system}

Control of visual system is daily carried out by normalization of a tone of an optic nerve. Then increase sensitivity of light reception. At first take a broad view without strain open eyes up of blueness a palate, and then look afar at a green meadow or green trees, having raised a nape to the sun. Then increase sensitivity of flasks of a retina of an eye, looking in the direction of the sun with the closed centuries in the morning, trying to see the sun through eyelids. This exercise helps to focus the image of the sun on a yellow spot. Further you adjust an eyeball on perception of forms, color and detail of distant and near object the arc review of the current environment on a vertical and a horizontal.

Control to dynamics of vision, normalization of frequency of fluctuation of a retina of an eye, is promoted by outdoor games with a ball in volleyball, tennis and others.

To the person wearing glasses before increasing sensitivity of visual system, it is necessary to rise at first a tonus of visual hillocks on a nape rotary massage clockwise wool. Then strongly to narrow eyes for a minute, and then to open slowly. To do exercises without points several times.

In the morning and in the evening within 10 minutes it is necessary to wash out eyes alternately warm and cool water. Such procedure perfectly keeps vision for many years, and is prophylaxis from many eye diseases, in particular a cataract and glaucoma.

The perception of forms, color and details of distant and near motionless and moving objects is result of control (Figure 1).

\section{Acoustical system}

Exercises for hearing control:

i. To rub palms of arms, to put warm palms on ears, to take, triturate ears;

ii. To bend down the top part of an ear down, to do rotary motions clockwise and against an hour hand;

iii. To press an ear lobule of an ear and to massage, (exercise also promotes improvement of vision); iv. To insert long fingers into ears, to press in turn the right and left finger.

The perception of the speech of interlocutors, music, sounding of the nature, singing of birds and other sounds is result of control.

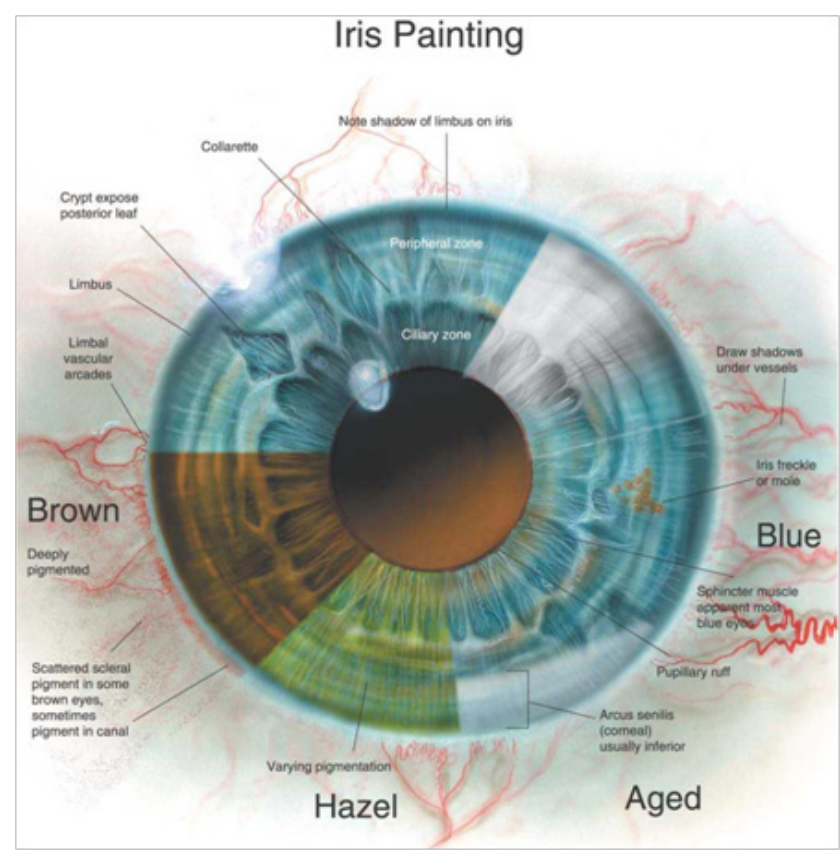

Figure I Eye iris.

\section{System of adaptation}

The system of adaptation customizes in the morning the vital systems of an organism outdoors in parameters and signals of the environment. The system of adaptation normalizes functioning of an organism and keeps its healthy functioning in the current conditions of the environment when the person moderately and in due time is engaged in physical exercises and carries out natural measures of normalization of vital systems. The normal health is result of control.

\section{System of a thermoregulation}

The thermoregulation should be begun in the morning after a dream with air bathtubs. Duration of air bathtubs from $3 \mathrm{~min}$. at the room temperature is gradually brought to $1.5-2 \mathrm{~h}$. 10-15 days later air bathtubs combine with circulation on a grass barefoot. The major factor influencing the person air temperature. The air layer between a body and clothes usually has constant temperature about $27-28^{\circ}$ and as soon as the body of the person is exempted from clothes, the thermolysis becomes more intensively at once. Irritating the nervous terminations of a skin, air improves saturation of blood oxygen, and its movement reflex strengthens processes of heat generation and a thermolysis to begin reception of air bathtubs it is necessary to begin in previously aired room. Then they are accepted in the open air. It is necessary to undress as much as possible that the air bathtub made impact on all surface of a naked body at once and I caused a fast thermoregulation of an organism. It is impossible to allow feelings of chill, emergence of goose-pimples. At the same time it is recommended to do several vigorous physical exercises, to be run. Air procedures the first step to a thermoregulation. After their reception within 3-4 weeks it is possible to pass to hydrotherapeutic procedures.

Special attention at the same time should be paid to usually closed parts of a body, especially feet of legs. Daily washing of legs by the 
water having temperature $28-30^{\circ}$ with the subsequent depression of temperature on $1-2^{\circ} \mathrm{C}$ and finishing it up to $15-16^{\circ} \mathrm{C}$ is for this purpose recommended every 5-7days. It is impossible to bring organism to a cold fit at all. At the first signs of overcooling it is necessary to do several physical exercises or to be pounded by a towel. It isn't necessary to force. Thermal control has to bring elation, feeling of joy and the updated body. If you have feeling of discomfort, it is better to change the mode of procedures. It is necessary to remember that long breaks (more than 2 weeks) lead to partial or full loss of the acquired reactions.

The water having the big thermal capacity and flowability very closely adjoins to a skin and has temperature-controlled effect. It is recommended to take a shower at least once a day. It is not just hygienic cleaning procedure, but a powerful tool of a thermoregulation of an organism, rising of a tonus of a nervous system. It is possible to refer to hydrotherapeutic temperature-controlled procedures also swimming. Impact on an organism solar beam, one of ways of a thermoregulation. Thermos exchange normalization is result of a thermoregulation.

\section{Physiological normalization}

Since morning, after a dream activate diffusion of the energy which collected in joints during sleep on all power channels of an organism joint charging. Joint charging sets energy of joints in motion and refers it on power channels. During joint charging it is necessary to support respiration. Charging shouldn't break respiration. Can do since morning the following moderate exercises on joint charging:

\section{Exercises for hand joints}

To rotate hands on 7 times clockwise and counterclockwise.

\section{Exercises for elbow joints}

To rotate radial bones of arms on 7 times clockwise and counterclockwise.

\section{Exercises for shoulder joints}

i. To put legs at shoulder length, to rotate brachium's forward and back ( 7 times in each party);

ii. Similarly previous, only to rotate straight arms ( 7 times in each party).

\section{Exercises for hip joints}

Standing:

i. Lifting of a leg forward and its abduction back

ii. Abduction of a leg and arm aside. Speed only slow (7 times);

iii. Standing, socks together. An inclination forward to try to get a floor the extremities of fingers or palms. Speed average (7 times).

\section{Exercises for knee joints}

i. Active alternate flexion and leg extension in knee joints. Speed average (on 7 times).

ii. Exercises for ankle joints and joints of foot:

iii. Lifting on socks and lowering on all foot Lifting of socks and lowering on all foot. Speed slow (on 7 times).

iv. The springing movements on tiptoe to try to lower a heel as low as possible. Speed average ( 7 times). v. Standing on tiptoe, carry out the elastic movements, bending and unbending legs in ankle joints of 7 times.

\section{Exercises for all joints of the lower extremity}

Standing:

i. Alternate lifting of legs forward, bending them in knee and hip joints. Speed slow (7 times);

ii. Semi-squat. Speed slow (7 times)

iii. Deep squat. Speed slow (7 times).

To hang a back to wall bars:

i. Alternate and simultaneous lifting of the legs bending in knee joints;

ii. Alternate and simultaneous lifting of direct legs. Speed slow (7 times).

After joint charging test power channels. Straighten a backbone and relax an organism, get up on toes, extend arms forward, finger-tips are slightly raised concerning palms. Then, concentrate attention on finger-tips of arms and legs. When there is a feeling of power gearing, it means that circulation of energy in power channels is carried out. The adjusted power channels will strengthen earth core current via the power channel of a backbone.

The enzymes of the nervous centers of absorption of light energy containing silicon promote its accumulation. Silicon accumulates solar energy and turns it into electric. It is necessary to counterbalance accumulation of various light energy by seven nervous centers. For this purpose it is necessary to lay down a breast on a green grass, to lift and extend arms and legs. To relax completely an organism. And doing cottons by arms before the head and behind the back, to try to obtain feeling of ease of flight by relaxation of an organism. Then to rise and check equilibrium of the nervous centers rotary massage clockwise. The centers are counterbalanced if there is no pain at massage of each of them. Then it is necessary to adjust 12 steam rooms of power channels of internals the coxofemoral movements by walking forward. The coxofemoral physical culture customizes twelve didymous power systems of internals through a backbone (Figure 2).

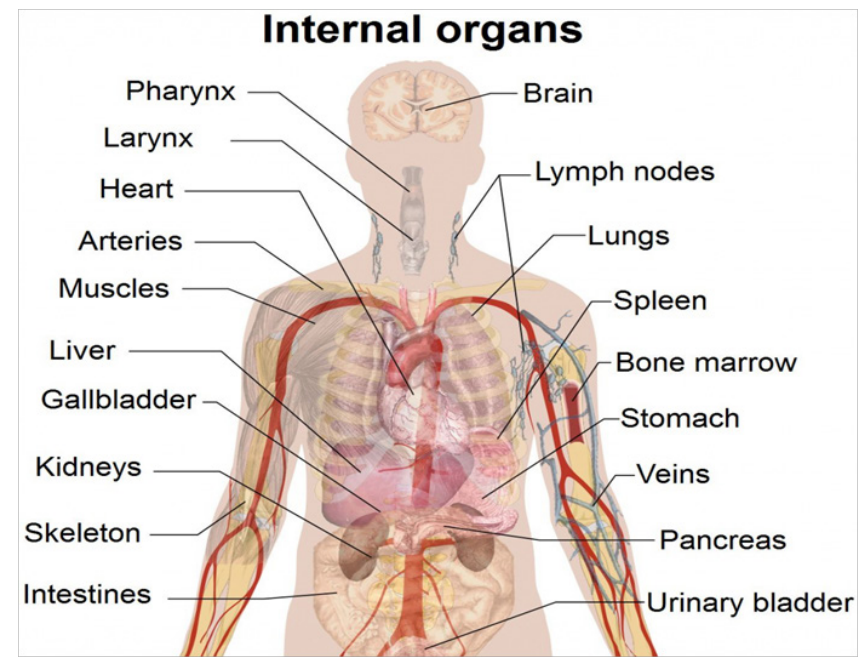

Figure 2 System of internals.

Traffic jams which appear in power channels are eliminated with purification of a power system (Figure 3). The different people have 
the culture of purification of a power system of an organism a broom in a bath. Normalization of endurance and good health is result of control.

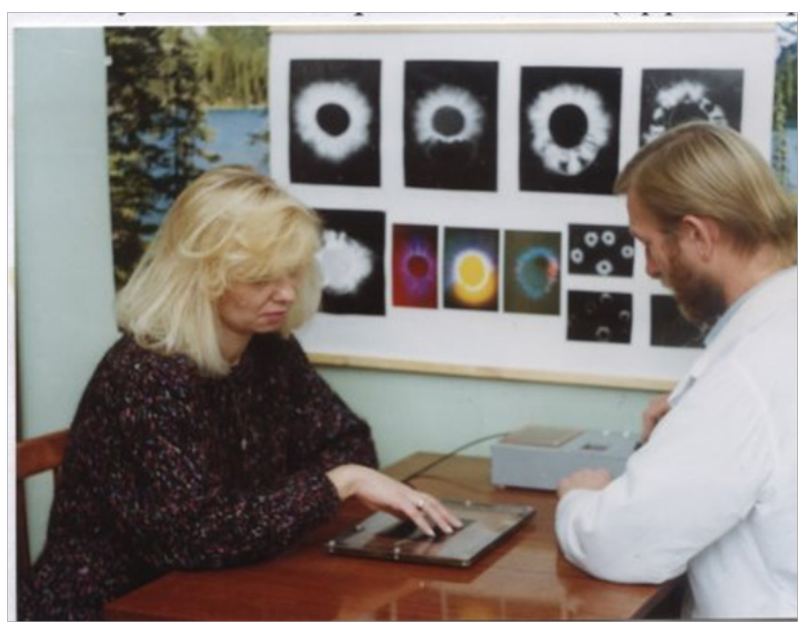

Figure 3 Traffic jams which appear in power channels are eliminated with purification of a power system.

\section{Normalization nervous system}

The person needs to support exaltation and inhibition of a nervous system in the course of social activity according to a natural daily cycle. Since morning to 17 o'clock in the afternoon active functioning of an organism is recommended, and after 17 hours and to a dream quiet functioning of an organism is recommended. Such daily rhythm of functioning of an organism maintains equilibrium of exaltation and inhibition of a nervous system. Equilibrium of processes of exaltation and inhibition of a nervous system according to a daily cycle of the Nature provides healthy physiology of an organism. In the course of social activity it is necessary to counterbalance mentality to keep equilibrium of exaltation and inhibition of a nervous system.

The good health during the day and sound sleep has to be result.

\section{Normalization muscular system}

The exercise stress is one of the most important agents of strengthening of muscular system of a musculoskeletal system. Everyday physical exercises bring huge benefit. In the morning physical exercises have to be referred on sprain, augmentation of flexibility and increase in elasticity of muscles. Carry out in clinations, turns, moves, extensions. To make small jog - but it is better to run and go on the soft earth that the backbone had no continuous blows and vertebral disks weren't deformed. After run it is recommended to hang for a while several minutes on a crossbeam to restore intervertebral disks and to keep elasticity and flexibility of this organ, extremely important for health.

Control of a tonus of muscular system is carried out by means of physical exercises for joints, arms and a neck, a shoulder girdle, for a trunk and a stomach, for legs, and exercises of complex control. Adjusting exercises are selected depending on a condition of an organism taking into account a seasonal cycle. For example, in the spring adjusting exercises have to raise a tonus of muscular system according to the increased power influence of the environment.

Now there are many systems of exercises at various people. In a technique are offered to exercise use which adjusts a musculoskeletal system in the preventive centers. It is possible to make a complex for control of these exercises for arms, a neck, brachium's, a waist, a back, a press, breeches, gastronomies muscles, a breast, and hips. Normalization of a tonus of an organism has to be result of control.

\section{Normalization immune system}

The immune system is customized by hardening of an organism on air and in water. It is previously necessary to customize the system of a thermoregulation. Hardening of an organism for control of immune system with emotional fixing is carried out no more than a month not to break balance of inhibition and exaltation of a nervous system and not to narrow the capillaries feeding organism cells (Figure 4). The good health has to be result of control.

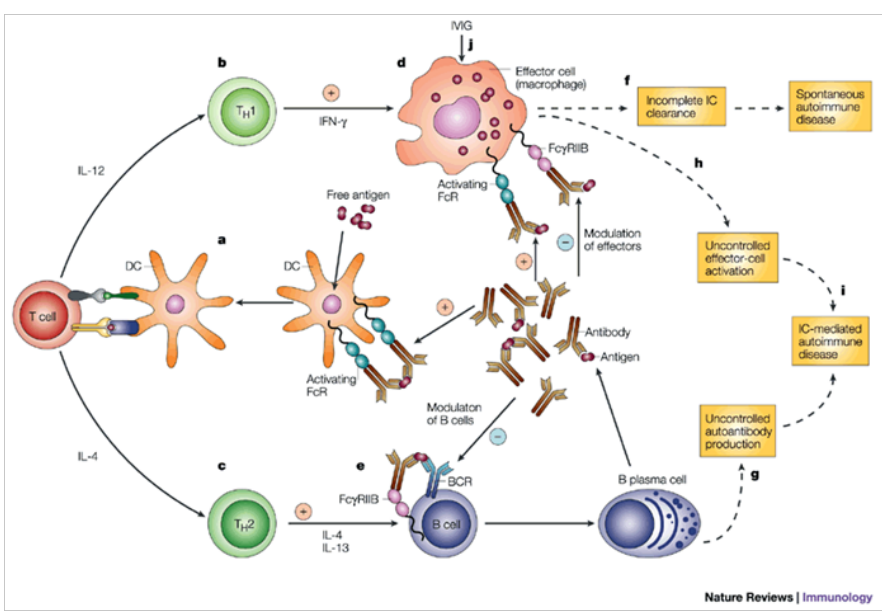

Figure 4 Immune complex.

\section{Normalization hormonal system}

The hormonal system is customized in the morning outdoors through the system of adaptation and a hypothalamus for ensuring hormonal equilibrium of an organism with development of neurotransmitters. Hormonal equilibrium is during the day maintained by the system of adaptation, a hypothalamus and through a metabolism enzyme, is the most effective bilberry enzymes. It is necessary to use bilberry for normalization of hormonal equilibrium in day on 50-100grams. For normalization of a hormonal background it is necessary to use sea-buckthorn oil. The use of sea-buckthorn oil on a teaspoon counterbalances during the lunchtime a hormonal background of including and switching off of genes of cells of an organism with hormones as genetic inductors. Equilibrium of production of hormones and delivery to their cells of an organism is result of hormonal control.

\section{Normalization circulatory and vascular system}

The circulatory and vascular system has to provide a normal circulation. The normal circulation feeds all cells of an organism and supports metabolic processes. Vessels have to be plastic and clean. The silicon nutrition does vessels plastic. Vessels periodically by infusion three the triturated lemon and three heads of garlic in two liters of water are cleaned. To accept daily on $50 \mathrm{ml}$ in 30 minutes prior to food. Exercise stresses strengthen muscles of vessels and improve a circulation. Rutinum very well strengthens blood vessels, protects an organism from bleeding and hemorrhages, reduces a blood clotting time, strengthens reductions of a cardiac muscle, slows down a cordial rhythm. The buckwheat contains rutinum. 
The blood has to be clean that vessels were clean.

The blood is periodically cleaned by fresh juice from beet, black radish and carrots on one glass with addition of one glass of honey. To accept daily 30 grams to food 3 times a day.

Exercises for cleaning and strengthening of capillaries:

i. To lie down on a back, having extended arms and legs up, then to vibrate them.

ii. To lie down on a back, to raise legs up, to extend socks and to vibrate legs and a trunk.

iii. The clean blood and clean plastic blood vessels have to be result of all actions.

\section{Normalization emotional system}

The emotional system participates in formation of healthy habits of the person. Spiritual consciousness results the person in useful effects, and the emotional system sets them as healthy habits within a month.

Useful effects are carried out by emotional feelings, such as joy, love, laughter, happiness, respect, consent, trust, creative achievements, belief, hope, forgiveness, the help, mercy, blessing, a care, justice, a smile, pleasant memories, good meanings, the moral relations which develop positive emotions. As a result of emotional control the mentality is counterbalanced, and useful effects within a month as useful habits are fixed.

\section{Self-restoration of an organism at the cellular level}

The condition of an organism depends on a qualitative condition of cages. Through the system of cellular self-restoration of an organism the healthy condition of cages at the spiritual, power, physiological and anatomic levels is reached. At the spiritual level the healthy state is reached by peace spirit. At the power level charging and pure ecology, at the anatomic level physical culture, normal poses in operating time, rest, acceptance of food and a dream. At the physiological level gymnastics, control of vital systems, healthy food, pure ecology, coordination of activity with a natural daily cycle. The main processes of self-restoration of an organism at the physiological level are hormonal balance, metabolism and regeneration. For normalization of metabolism it is necessary to pass to alkaline food, having excluded from a food allowance cancerogenic, received by chemical processing, the food containing mutational proteins; to drink clear water.

At normal metabolism hormonal balance requires coordination of activity with a natural daily cycle. When the natural rhythm of a dream and wakefulness is broken, then hormone melatonin is produced insufficiently, the hormonal balance in an organism is broken and, as a result, the mechanism of cellular updating is broken, and cages can increase, or regenerate. That process of dying off of the regenerated cages has begun it is necessary to suspend their mutational genes genetic inductors (hormones). It is reached by hormonal balance on production of hormones and normalization of a hormonal background on delivery to their cages. For establishment of hormonal balance production of hormone of melatonin by epiphysis in enough is necessary. At daylight melatonin isn't produced. Melatonin is produced at night during sleep. For this purpose it is necessary to adjust first of all the dream mode for the purpose of production of hormone of melatonin in enough. For full production of hormones hormonal system it is necessary to come after a dream to the nature for coordination of the internal and external environment through the system of adaptation for the purpose of development of neurotransmitters a hypothalamus, then before a breakfast using bilberry for maintenance of hormonal balance and before a lunch a sea-buckthorn for normalization of a hormonal background.

Cell regeneration is carried out in the course of their division through a metabolism, in case of normal metabolism and hormonal equilibrium. Regeneration of disks of vertebras and cartilaginous tissue of joints is carried out in the course of uniform walking. In case of uniform walking regeneration of cartilaginous tissue compensates its erasing. After 20 minutes of uniform walking a supply of cells of vertebras due to diffusion and also regeneration process begins. Complete regeneration of disks of vertebras is carried out in 1,5-2 hours of uniform walking, 64 steps a minute.

To normalize the mechanism of cellular up-dating (regeneration) it is necessary to customize daily vital systems and integral functioning of an organism at the spiritual, energetic, physiological and anatomic levels. For maintenance and formation of a healthy status through the system of cellular self-recovery of an organism it is necessary

A. To provide the vibrational frequency of cells of 8 hertz 8 meters long and their resonance with earth kernel current integral setup of an organism, peace spirit, activity under the law of conscience which is registered in heart (a spirit room) of everyone in case of the birth, manifestation of spiritual qualities. The spiritual person has the vibrational frequency of cells of 8 hertz 8 meters long in each cell.

B. To support organism rhythms through the system of internal breathing by uniform walking 64 steps a minute with combined, belly, chest, guttural and pneumatic bosoms, breathing on 4 steps the breath and steps exhaled through a nose for saving a resonance of frequencies of healthy cells their complete interference.

C. To support at the energy level a resonance of frequencies of healthy cells by earth kernel current which passes through the energetic channel of a backbone, elimination of energetic corks in energetic channels and integral setup of a power system of an organism.

D. To support regeneration of healthy cells by peace spirit, a healthy supply, a metabolism, normalization of rhythms of functioning of an organism, setup of vital systems, integral setup of an organism, activity in the favorable natural and social environment in the summer, in the fall, in the winter and in the spring.

E. Levels and measures of adjustment of a condition of cells, in difficult essence of the person the mechanism of change of a qualitative condition of cells is put. The person via this mechanism both gets sick and recovers by high-quality change of a condition of cells at the spiritual, power, physiological and anatomic levels.

At a healthy lifestyle the qualitative condition of stem cells in the course of differentiation most productively improves. Stem cells are capable to be updated, forming new stem cells, to share by means of mitosis and to be differentiated in specialized a cell, which is to turn into cells of various organs and tissues. 
Development of an organism begins with one stem cell. As a result of numerous cycles of division and process of a differentiation all types of cells are formed. In a human body of types of cells more than 200. Stem cells remain and function also in an adult organism, on the basis of their organism can carry out updating and restoration of tissues and organs. Nevertheless, in the course of aging of an organism their quantity decreases.

The quantity and concentration of stem cells in umbilical blood are higher, than in other sources. In $100 \mathrm{ml}$ of umbilical blood contains as much stem cells how many in 1 liter of marrow. At the birth of the person on 10000 all cells one stem cell, at teenage age one is the share of 100000 cells, and at advanced age already one of 500000 cells. Most of all stem cells in umbilical blood.

All stem cells have two integral properties:

i. Self-updating, that is ability to keep an invariable phenotype after division (without differentiation);

ii. The differentiating potential or ability to give posterity in the form of specialized types of cells.

There are two mechanisms supporting population of stem cells in an organism:

i. Azygomorphous division at which the same couple of cells (one stem cell and one differentiated cell) is produced.

ii. Stochastic division: one stem cell is divided into two more specialized.

The fabric specific low-differentiated cells predecessors which settle down in various tissues and organs and are responsible for updating of their cell population, that is replace the dyed cells. Some cells of an adult organism have ability to generate the stem cells characteristic of an embryo. Stem cells are precursors of one and all types of cells in an organism. They are capable to self-updating. In certain conditions they are capable to turn into specialized cells of various tissues and organs: blood cells, it is warm - vascular system, a liver, bone and cartilaginous tissue and others. The stem cell can become practically any cell in a human body.

At the earliest stages of the development the germ completely consists of stem undifferentiated cells, then stages of a differentiation begin and organs and body tissues are formed of them. In an adult organism stem cells contain in small amounts in a blood and marrow and in smaller quantities in all organs and tissues. As these cells can be transformed to cells of any organs and tissues, they play a role of some kind of emergency help: if somewhere in an organism the malfunction, stem cells are referred there and, being transformed to cells of the damaged organ, promote restoration of its function. Improvement of a qualitative condition of cells needs to be carried out at all levels.

\section{Spiritual level}

Reason and soul, generating an emotional thought, form a wave of mental energy. The spirit penetrates it all cells. It through a wave genome starts the genetic mechanism which creates conditions for a metabolism, homeostasis..$^{1-5}$ The metabolism frames a qualitative condition of cells. The negative emotional thought worsens mentality and a qualitative condition of cells.

The positive emotional just thought improves mentality and a qualitative condition of cells. The Creator defined measures of spiritual level of healthy human life. Improvement of a condition of cells at the spiritual level is carried out by mental energy of true consciousness. The pure mind does spirit light. The light spirit does healthy a body.

\section{Power level}

Improvement of a qualitative condition of cells at the power level is carried out through power systems of the person:

i. Nervous centers of absorption of light energy

ii. Biofield6

iii. Power channels of an organism7

iv. 12 pair channels formed by internals 8

v. Visual system

vi. System of a thermoregulation

vii. System of electromagnetic intercellular interaction

\section{Physiological level}

Improvement of a qualitative condition of cells at the physiological level is carried out:
a. Through a metabolism ${ }^{9}$
b. Purification of an organism
c. Respect for hygiene
d. Stay in the clean environment
e. Vital activity regimen
f. Control of functioning of vital systems and all organisms.

\section{Anatomic level}

Improvement of a qualitative condition of cells at the anatomic level is carried out:

i. Neogenesis and normal poses at the movement, standing, sitting, during sleep.

ii. Physical culture, gymnastics, charging.

\section{Resultant integrated control of an organism}

At first the system of coordination, in the course of coxofemoral walking is customized. Then through the system of coordination integrated control of an organism in the course of walking by hip joints forward and back with simultaneous complex control of respiration, vision, a tonus, thermoregulation, adaptation, a power system, emotional system and rhythms, neogenesis of a backbone is carried out. During complex control of an organism integrated coordination of horizontal nervous formations of all vital systems with a vertical nervous system of coordination is carried out.

It is better to perform integrated tuning of an organism at solar morning light. Under the influence of sunlight the tonus of the central nervous system raises, activity of endocrine glands is stirred up, barrier function of a skin, a metabolism and structure of a blood improve, the blood circulatory system and immunity become stronger, the vitamin D playing an important role in phosphorus-calcium exchange, supporting in the normal state of a bone and teeth is produced. As a result of integrated control the person has a good health and a healthy condition of its difficult essence. ${ }^{10-15}$ 


\section{Conclusion}

Relevant is a process of formation of the international scientific communities aimed at development of applied scientific research using digital platforms and network forms of cooperation on detection of natural measures of normalization of vital systems of the person and formation of infrastructure of health care on the basis of a healthy lifestyle (Figure 5).

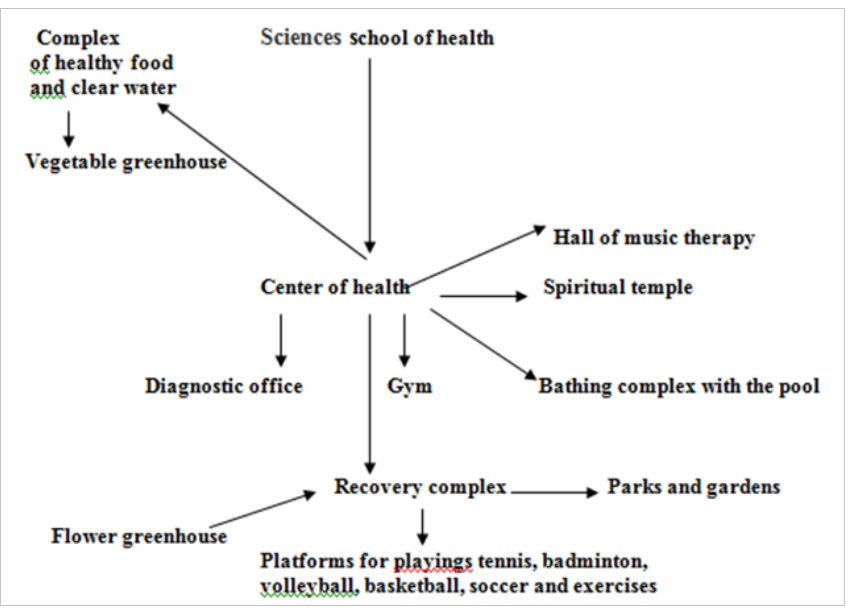

Figure 5 Infrastructure for maintaining of health.

The main development of the modern health care there shall be a formation at the population of a healthy lifestyle. ${ }^{11-15}$ For this purpose it is necessary to create health the preserving medicine. The role of the doctor health of the preserving medicine consists in implementation of natural measures of normalization of vital systems of a difficult entity and a healthy lifestyle of patients. Increase in motivation at the population to natural measures of normalization of an organism and to a healthy lifestyle shall be the purpose of the modern health care. Tasks of the modern health care becomes shall: formation health of creative outlook of the population, lecturing and distribution of literature on natural-science aspects of health and a healthy lifestyle, an involvement of citizens in improving spiritual and sports collective actions, acquisition by citizens of all categories of the useful habits. To provide mass accessibility of the population to objects of physical culture: to stadiums, gymnasiums and platforms, pools. To provide a healthy supply and access to clear water and also diagnostics of a physiological status of citizens; To organize for the population of an action for formation of family and public culture of a healthy lifestyle; To provide physical, energetic and spiritual cleaning to citizens; To rely on health the supporting economy and ecology of the environment.

\section{Acknowledgements}

None.

\section{Conflict of interest}

The author declares no conflict of interest.

\section{References}

1. Bryndin EG. Activities of a brain, longevity and healthy lifestyle International conference, Achievements of Neuroscience for the Modern Medicine and Psychology. USA: Springer; 2005. p. 47-49.

2. Bryndin EG. Technology of integral improvement and health of saving. International conference Fundamental and Application-oriented Problems of a Stress, USA: Springer; 2011. p. 1-9.

3. Bryndin EG, Bryndina IE. Bases of the healthy person and society. TPU: Scientific publication; 2011.302 $\mathrm{p}$.

4. Darneva IS, Rachkovskaya LN. Quality of life: natural-science aspects. Novosibirsk: CJSC IPP of set; 2014. 124 p.

5. Bryndin EG. Development of improving abilities of students. Physical culture and sport at the present stage: problems, search, decisions: Materials of an interregional scientific and practical conference-Tomsk, TPU: Springer; 2011. p. 76-80.

6. EG Bryndin, Bryndina IE. Healthy lifestyle. S-PB: Scientific and practical log. Donozologiya and Healthy Lifestyle; 2012.p. 70-76

7. Evgeny B, Irina B. Bases of healthy longevity. Germany: Lambert Academic Publishing; 2012. $225 \mathrm{p}$.

8. Bryndin EG, Bryndina IE. How to transfer to a healthy lifestyle. TPU: Springer; 2013. $288 \mathrm{p}$.

9. Bryndin EG. Aspects of a healthy lifestyle. International scientifically practical conference: The healthy urban environment, healthy life and overcoming inequality in health; 2013. p. 100-107

10. Bryndin EG, Bryndina IE. Health the preserving medicine - future medicine. The $9^{\text {th }}$ Euroasian conference Donozologiya 2013-Problems of development and use of nanotechnologies in the modern preventive medicine; 2013. p. 58-60.

11. Bryndin EG, Bryndina IE. Natural-science aspects of health. Weber Medicine \& Clinical Case Reports. 2015;1:134-137.

12. Bryndin EG, Bryndina IE. Healthy wellbeing of the person and society. Journal The European Proceedings of Social \& Behavioural Sciences EpSBS. 2017;5(XIX ):130-139.

13. Bryndin EG, Bryndina IE. Sanatorium rehabilitation of the population by the healthy lifestyle. International journal Rehabilitation Sciences. 2017;2(2):35-40.

14. Bryndin EG, Bryndina IE. Normalization of psyche by healthy lifestyle of various groups of the population. American Journal of Applied Psychology. 2017;6(4):51-56.

15. Bryndin EG, Bryndina IE. Formation of public health care on basis of healthy lifestyle. International Journal of Psychological and Brain Sciences. 2017;2(3):63-68. 